\title{
340 nm Bandwidth Automatic Dynamic Optical Equalizer for CWDM Networks
}

\author{
Samuel H. Dupont, ${ }^{1,2,3}$ Jean-Claude Kastelik, ${ }^{1,2,3}$ and Joseph Gazalet ${ }^{1,2,3}$ \\ ${ }^{1}$ Université Lille Nord de France, 59000 Lille, France \\ ${ }^{2}$ UVHC, IEMN, 59313 Valenciennes, France \\ ${ }^{3}$ CNRS, UMR 8520, 59650 Villeneuve d'Ascq, France
}

Correspondence should be addressed to Samuel H. Dupont; samuel.dupont@univ-valenciennes.fr

Received 19 July 2013; Accepted 9 September 2013

Academic Editor: Michael Fiddy

Copyright (C) 2013 Samuel H. Dupont et al. This is an open access article distributed under the Creative Commons Attribution License, which permits unrestricted use, distribution, and reproduction in any medium, provided the original work is properly cited.

This paper presents an automatic optical equalizer based on a pair of in-house developed high efficiency, acousto-optic variable optical attenuators (AO-VOAs). The system is polarization insensitive and presents a wide bandwidth compatible with coarse wavelength division multiplexing $(C W D M)$ requirements: $340 \mathrm{~nm}$. The system operation is automatic and bidirectional and equalization is obtained in one single iteration of algorithm loop.

\section{Introduction}

In the context of an increasing demand for wideband transmission services, coarse wavelength division multiplexing is tackling access network capacity maximization. From the network management's point of view, the number of optical central offices has to be optimized for economic viability; such an optimization is shown to be possible using optical budget extension; with an amplification technique, the link between the subscriber and central office can be extended or the splitting ratio can be increased (i.e., the number of users) $[1,2]$. In this context, an intense activity is devoted to the development of enabling optical technologies to meet next generation distribution network challenges. A straightforward solution to increase the optical budget is to bring optical amplification technique into play; erbium doped fiber amplifier (EDFA), semiconductor optical amplifier (SOA), and Raman type amplifiers have been successfully tuned up to boost optical access networks [3-7]. However, the use of optical amplification requires optical equalization [8].

This paper presents a dynamic optical equalization setup that meets (for the first time to the best of our knowledge) the operation requirements across the full CWDM band: $340 \mathrm{~nm}$. This system is faster than fiber-based/MEMS-based equalizers [8-13]; it is more compact than MEMS-based equalizers
[10-12] and even than other acousto-optic based systems [10]. The system operation is bidirectional and fully automatic and the equalizer is able to adapt to all situations encountered during usual optical network processes-adding or dropping channels and input signal level variations. The operation principle is based on the cascade of two acousto-optic (AO) cells which are optimized for the modulation of near infrared signals; a complete description of the $\mathrm{AO}$ cells design and testing can be found in [14]. AO devices are known for their wide tuning range and their fast response time (down to the microsecond); they are naturally suited to multispectral filtering. We focus our investigations here on an automatic equalization function.

This paper is structured as follows. We first present the equalizer characteristics and then illustrate the main experimental results obtained from the equalizer. We conclude by drawing some perspectives.

\section{Equalizer Characteristics}

The aim of the setup is to benefit from modulation properties of two cascaded tellurium dioxide AO-VOAs to perform an automatic dynamic equalizer for CWDM signals. The main performances are found in Table 1. 
TABLE 1: Equalizer main characteristics.

\begin{tabular}{lcc}
\hline $\begin{array}{l}\text { Equalizer } \\
\text { characteristics }\end{array}$ & AO-VOA setup & Recommendations $^{\mathrm{b}}$ \\
\hline Bandwidth & $>340 \mathrm{~nm}$ & $/$ \\
Dynamic & $20 \mathrm{~dB}$ & $20 \mathrm{~dB}$ \\
Resolution & $0.1 \mathrm{~dB}$ & $0.2 \mathrm{~dB}$ \\
Response time & $\sim \mu \mathrm{s}^{\mathrm{a}}$ & $30 \mathrm{~ms}$ \\
Insertion loss & $2 \mathrm{~dB}$ & $<6 \mathrm{~dB}$ \\
\hline
\end{tabular}

${ }^{\mathrm{a}}$ Correspond to AO-VOA response time; ${ }^{\mathrm{b}}$ References $[15,16]$.

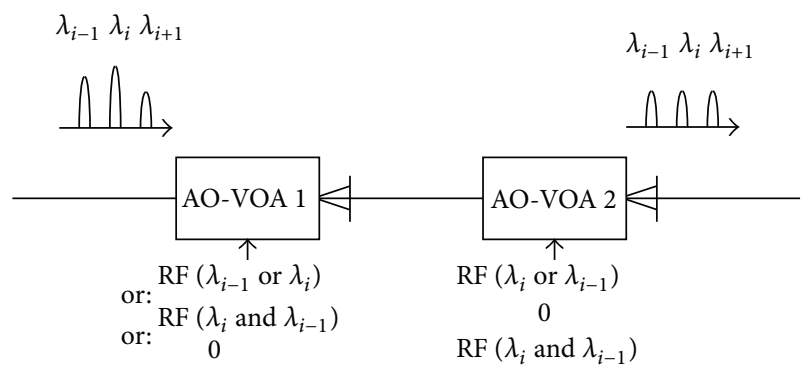

FIgUrE 1: Cascaded AO-VOA cells principle; input and equalized output spectra are shown for illustration, together with possible combinations of rf. driving conditions of the cells to get an equivalent equalization.

Acousto-optic devices have been proposed for the filtering of WDM signals [17]. As reported, acousto-optic interaction is polarization dependent in anisotropic acousto-optic crystals such as $\mathrm{TeO}_{2}$. On the contrary, in optical networks the components have to process light without a specific polarization. Each of the two AO-VOAs used in our setup are polarization sensitive, although the overall operation of the system is polarization independent; the incident beam with arbitrary polarization is split in the first cell into two adjacent beams with orthogonal polarizations, but the second $\mathrm{AO}$ cell, cut from the same crystal, is placed symmetrically to the first one to compensate exactly for the birefringence of the first crystal. Moreover, the cells are designed to obtain simultaneous diffraction by the same acoustic wave of both polarizations in the +1 and -1 diffraction orders. These beams are blocked at the output of both cells by diaphragms (Figure 1). As a result of simultaneous diffraction, the transmitted beam is attenuated with an efficiency being insensitive to the polarization of the incoming light. Either of the two cells can independently process any of the incoming optical signals. Several possible driving conditions are illustrated in Figure 1, with all resulting in the same overall equalization. From the cells design, a perfect bidirectional operation capability is possible.

The AO cells rf. tuning bandwidth for CWDM wavelengths is comprised between $41 \mathrm{MHz}$ and $55 \mathrm{MHz}$ (Figure 2). The input and output facets are cut orthogonal to the incident beam for a simple alignment with transmitted beam. They are coated with antireflection layers; maximum reflectivity is less than $0.6 \%$ in the CWDM band. The fiber-to-fiber loss is measured to be lower than $2 \mathrm{~dB}$ when the AO-VOAs are inserted in a fiber gap composed of a pair of focusers. The filtering

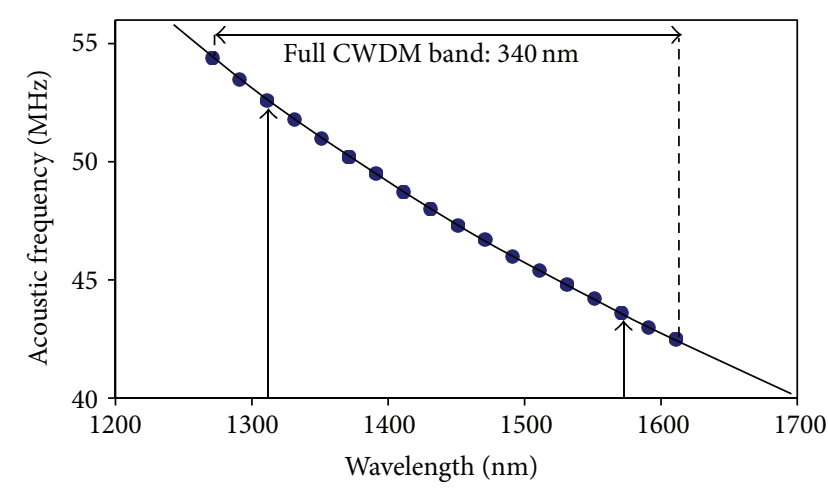

FIGURE 2: AO-VOA tuning characteristics; each dot corresponds to a $20 \mathrm{~nm}$ spaced CWDM channel; most distant channels experimentally tested are highlighted $(1310 \mathrm{~nm} ; 1570 \mathrm{~nm})$.

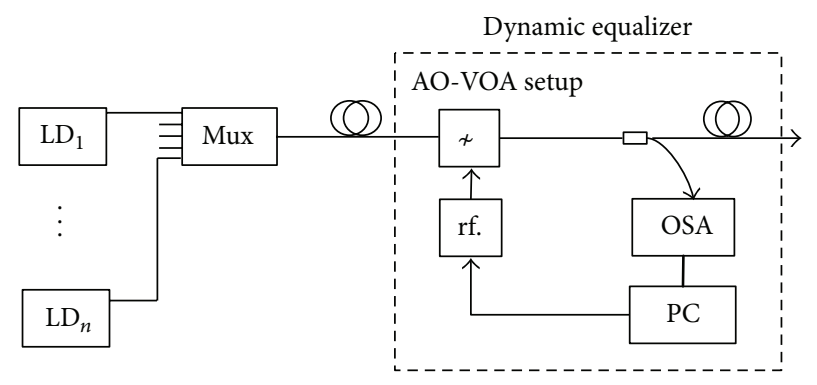

Figure 3: Experimental setup; LD: laser diode; Mux.: multiplexer; rf.: rf. driving setup composed of two generators and two amplifiers; OSA: optical spectrum analyzer.

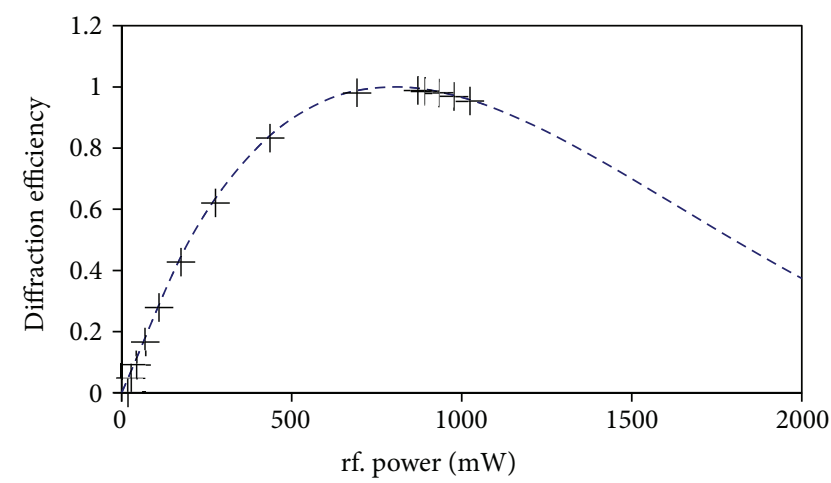

FIgURE 4: Typical diffraction efficiency of an AOTF plotted versus rf. driving power. Cross: measured values at $1310 \mathrm{~nm}$, dashed curve: fitted function.

characteristics of the AO-VOAs are frequency dependent; the passband $\Delta \lambda$ of the cells is $\Delta \lambda=7.2 \mathrm{~nm}$ at $1270 \mathrm{~nm}$ and $\Delta \lambda=$ $11.5 \mathrm{~nm}$ at $1610 \mathrm{~nm}$, well adapted to the filtering of CWDM channels. The rf. power for extinction is measured to be comprised between $0.8 \mathrm{~W}$ at $1310 \mathrm{~nm}$ and $1.85 \mathrm{~W}$ at $1570 \mathrm{~nm}$. An experimental extinction ratio of at least $20 \mathrm{~dB}$ has been measured for all carriers tested; we have kept this value as the dynamic of the equalizer in Table 1, meeting the ITU recommendations $[15,16]$. If needed, the activation of both cells 

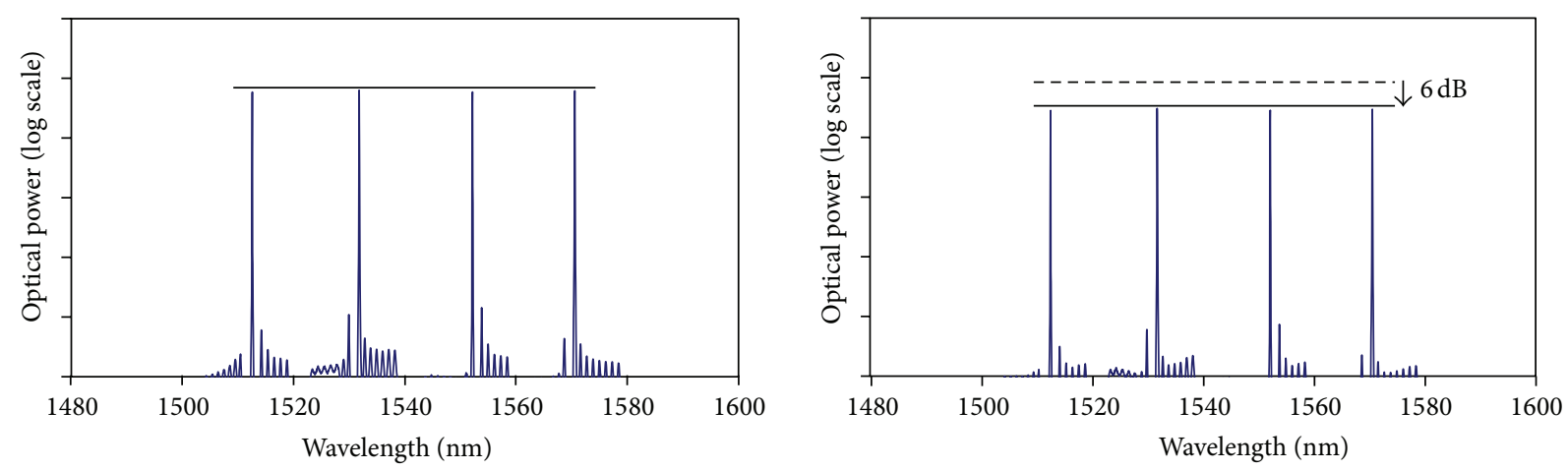

(a)
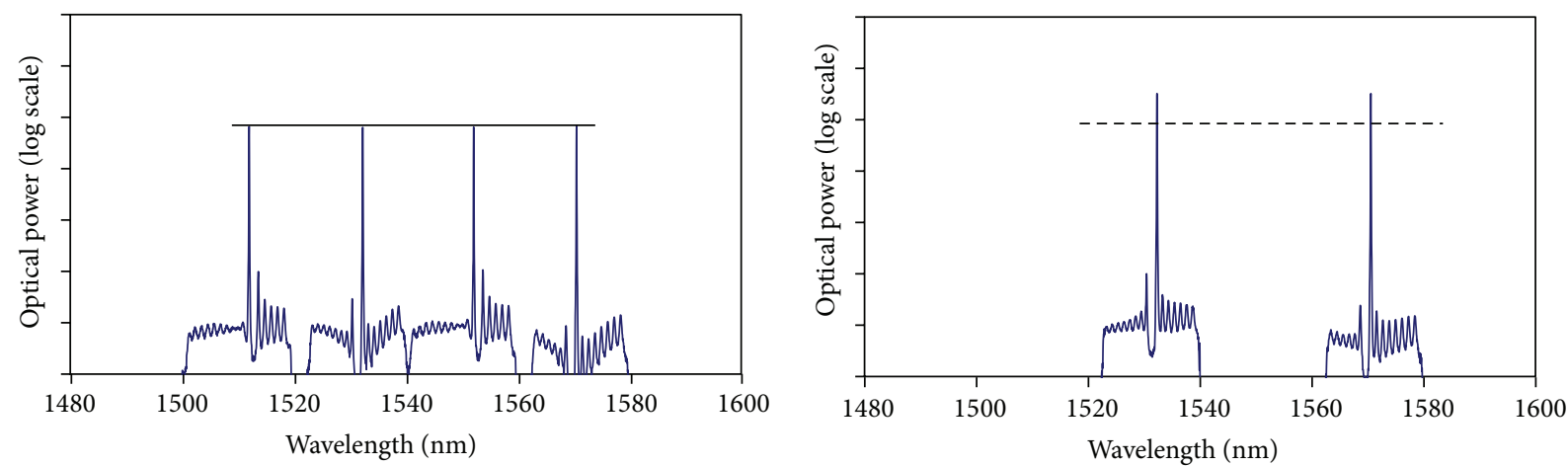

(b)
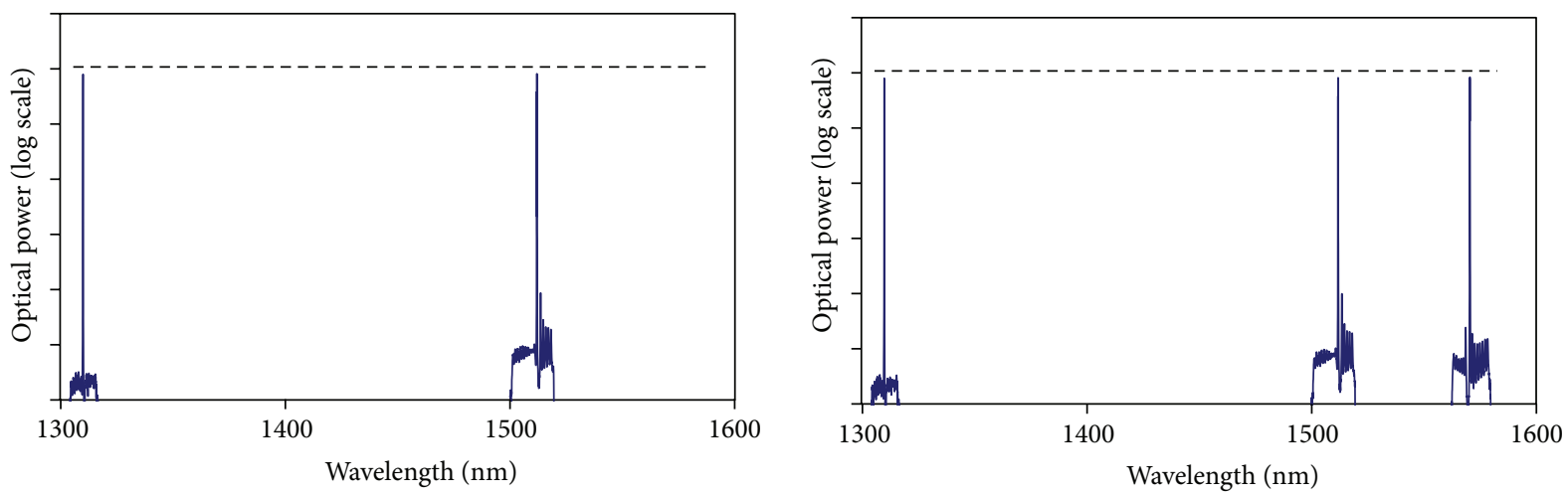

(c)

FIGURE 5: Spectrum at the output of the equalizer; (a) multichannel operation: a single AO-VOA attenuates 4 channels; (b) dropping channels; (c) adding a channel.

with a frequency corresponding to the same channel results in $40 \mathrm{~dB}$ attenuation [18].

Interchannel interference is defined as the attenuation obtained in neighbors channels $\left(\lambda_{i \pm 1}, \lambda_{i \pm 2}, \ldots\right)$ when channel $\lambda_{i}$ is active. The worst case is the following situation. Channel $\lambda_{i}$ is attenuated at the maximum (not used in practice for an equalization function) and you evaluate the unwanted attenuation resulting in channels $\lambda_{i \pm 1}$. The inter-channel interference is no more than $0.5 \mathrm{~dB}$, experimentally verified.

\section{Equalization Results}

The experimental configuration is shown in Figure 3. Four CWDM lasers, spaced every $20 \mathrm{~nm}$ from $1510 \mathrm{~nm}$ to $1570 \mathrm{~nm}$, and one at $1310 \mathrm{~nm}$ are multiplexed into a single fiber (thus covering almost the full CWDM band). The optical power delivered by each laser diode is in the order of the mW. The dynamic equalizer is composed of a modulation part (the two cascaded AO-VOAs) and a feedback system; a 1\% coupler ensures signal tapping to monitor optical power with an optical spectrum analyzer (OSA), and a computer processes OSA signals and controls two rf. generators connected to amplifiers driving the two AO-VOA transducers. One of the two rf. generators is a four-channel direct digital synthesizer, all of its channels are amplified separately and summed by a passive combiner.

The transmission characteristics of both acousto-optic cells for each experimental channel have been fitted (Figure 4). 
A difference in the order of $0.1 \mathrm{~dB}$ is possible between the experimental values and the fitted transfer functions. This is in the order of the OSA resolution. With the fitted relations, we can compute attenuation values in accordance with equalization requirements.

The system is automated as follows. The OSA measures the parameters of the transmitted light with periodic scans over the entire CWDM band; that is, wavelength and optical power of all peaks are found $\left(\lambda_{i}\right.$ and $P_{\mathrm{O} i}, i$ refers to the number of the channel). Then the computer determines optimal driving conditions; interaction frequencies $f_{i}$ are calculated with the knowledge of peak wavelengths $\lambda_{i}$ from tuning characteristics (Figure 2) and rf. driving powers $p_{i}$ are calculated from the fitted diffraction efficiency curves (Figure 4). Finally, computed driving parameters are sent to the rf. generators. All operations are repeated in a loop. It is worth mentioning that the calculation of driving conditions at loop iteration number $n$ also requires the knowledge of driving conditions at iteration $n-1$ to be able to compute equalizer input optical signals from output optical measurements.

Figure 5 depicts the response of the system to typical equalization operation scenarios. First, we test the multichannel leveling operation; a single cell is activated to obtain attenuation simultaneously on four channels, and up to $6 \mathrm{~dB}$ for all channels is obtained (Figure 5(a)). For completeness, the four-channel rf. generator was connected to the second AOVOA and the test was successfully repeated. The attenuation value, $6 \mathrm{~dB}$, is sufficient for operation in distribution networks as higher fluctuations often arise from cascaded amplifier setup, such as for long distance networks.

Then various scenarios, reproducing the most common situations an equalizer has to deal with, are tested. As can be seen in Figure 5, the equalizer performance is satisfactory. Dropping channels is dealt with efficiently, Figure 5(b); note that the output level after dropping channels is set to the (new) minimum power of the remaining channels. Adding channels is also dealt with efficiently, Figure 5(c). For all cases tested, the system is able to equalize channels in one single iteration of the loop.

\section{Discussion}

We now consider equalization of all CWDM channels. With the experimental expense of adding a second four-channel rf. generator, the system is able to attenuate by $6 \mathrm{~dB}$ eight independent CWDM signals. The number of CWDM channels is precisely eight with standard single mode fiber $[15,16]$. In this case, there is a perfect match between the system capabilities as described and CWDM equalization requirements. With low water peak fiber, sixteen channels are expected to be operated. In this case, attenuation of all CWDM channels would be possible but with a lower attenuation value: $4 \mathrm{~dB}$. However, an rf. transducers design optimization can improve driving conditions.

As reported, a dynamic, automatic optical equalizer for optical networks has been setup and tested. This is the first demonstration of a dynamic equalizer able to operate over the full CWDM band. The characteristics of the equalizer will be useful in next generation CWDM networks.

\section{References}

[1] K.-I. Suzuki, Y. Fukada, D. Nesset, and R. Davey, "Amplified gigabit PON systems," Journal of Optical Networking, vol. 6, no. 5, pp. 422-433, 2007.

[2] P. Chanclou, Z. Belfqih, B. Charbonnier et al., "Access network evolution: optical fibre to the subscribers and impact on the metropolitan and home networks," Comptes Rendus Physique, vol. 9, no. 9-10, pp. 935-946, 2008.

[3] I. Khadijah, P. S. Menon, H. A. Bakarman et al., "Performance of 18 channel CWDM system with inline Semiconductor Optical Amplifier," in Proceedings of the IEEE 3rd International Conference on Photonics (ICP '12), pp. 215-219, October 2012.

[4] T. Miyamoto, M. Tanaka, J. Kobayashi et al., "Highly nonlinear fiber-based lumped fiber Raman amplifier for CWDM transmission systems," Journal of Lightwave Technology, vol. 23, no. 11, pp. 3475-3483, 2005.

[5] P. Iannone, K. Reichmann, and L. Spiekman, "In-service upgrade on an amplified 130-km metro CWDM transmission system using a single LOA with a 140-nm bandwidth," in Proceedings of the Optical Fiber Communication Confernece (OFC’ 03), Atlanta, Ga, USA, March 2003.

[6] H. J. Thiele, L. Nelson, N. J. Holmdel et al., "Linear optical amplifier for extended reach in CWDM transmission systems," in Proceedings of the Optical Fiber Communication Confernece (OFC '03), Atlanta, Ga, USA, March 2003.

[7] S. Park, R. Leavitt, R. Enck et al., "Semiconductor optical amplifier for CWDM operating over 1540-1620 nm," IEEE Photonics Technology Letters, vol. 17, no. 5, pp. 980-982, 2005.

[8] J. B. Rosolem, A. A. Juriollo, R. Arradi, A. D. Coral, J. C. R. F. de Oliveira, and M. A. Romero, "S-C-L triple-band double-pass erbium-doped silica fiber amplifier with an embedded DCF module for CWDM applications," Journal of Lightwave Technology, vol. 24, no. 10, pp. 3691-3697, 2006.

[9] S. Y. Park, H. K. Kim, G. Y. Lyu, S. M. Kang, and S.-Y. Shin, "Dynamic gain and output power control in a gain-flattened erbium-doped fiber amplifier," IEEE Photonics Technology Letters, vol. 10, no. 6, pp. 787-789, 1998.

[10] J.-X. Cai, K.-M. Feng, X. Chen et al., "Experimental demonstration of dynamic high-speed equalization of three WDM channels using acoustooptic modulators and a wavelength demultiplexer," IEEE Photonics Technology Letters, vol. 9, no. 5, pp. 678680, 1997.

[11] J. E. Ford and J. A. Walker, "Dynamic spectral power equalization using micro-opto-mechanics," IEEE Photonics Technology Letters, vol. 10, no. 10, pp. 1440-1442, 1998.

[12] N. A. Riza and S. A. Reza, "High-dynamic-range hybrid analogdigital control broadband optical spectral processor using micromirror and acousto-optic devices," Optics Letters, vol. 33, no. 11, pp. 1222-1224, 2008.

[13] J. K. Doylend, P. E. Jessop, and A. P. Knights, "Silicon photonic dynamic optical channel leveler with external feedback loop," Optics Express, vol. 18, no. 13, pp. 13805-13812, 2010.

[14] J.-C. Kastelik, K. B. Yushkov, S. Dupont, and V. B. Voloshinov, "Cascaded acousto-optical system for the modulation of unpolarized light," Optics Express, vol. 17, no. 15, pp. 12767-12776, 2009.

[15] International Telecommunication Union Recommendations, "Optical interfaces for coarse wavelength division multiplexing applications," ITU-T Rec G. 695. 
[16] International Telecommunication Union Recommendations, "Transmission characteristics of optical components and subsystems," ITU-T Rec G. 671.

[17] J. Sapriel, D. Charissoux, V. Voloshinov, and V. Molchanov, "Tunable acoustooptic filters and equalizers for WDM applications," Journal of Lightwave Technology, vol. 20, no. 5, pp. 892899, 2002.

[18] J. C. Kastelik, "Polarisation insensitive AO tunable notch filter," in Proceedngs of the International Congress on Ultrasonics (ICU '11), no. 1433, pp. 92-93, Gdansk, Poland, September 2011. 

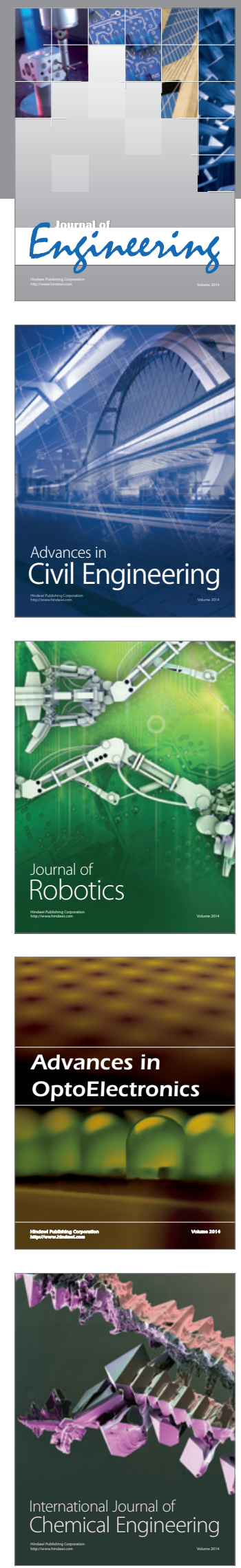

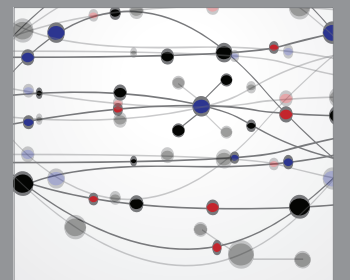

The Scientific World Journal
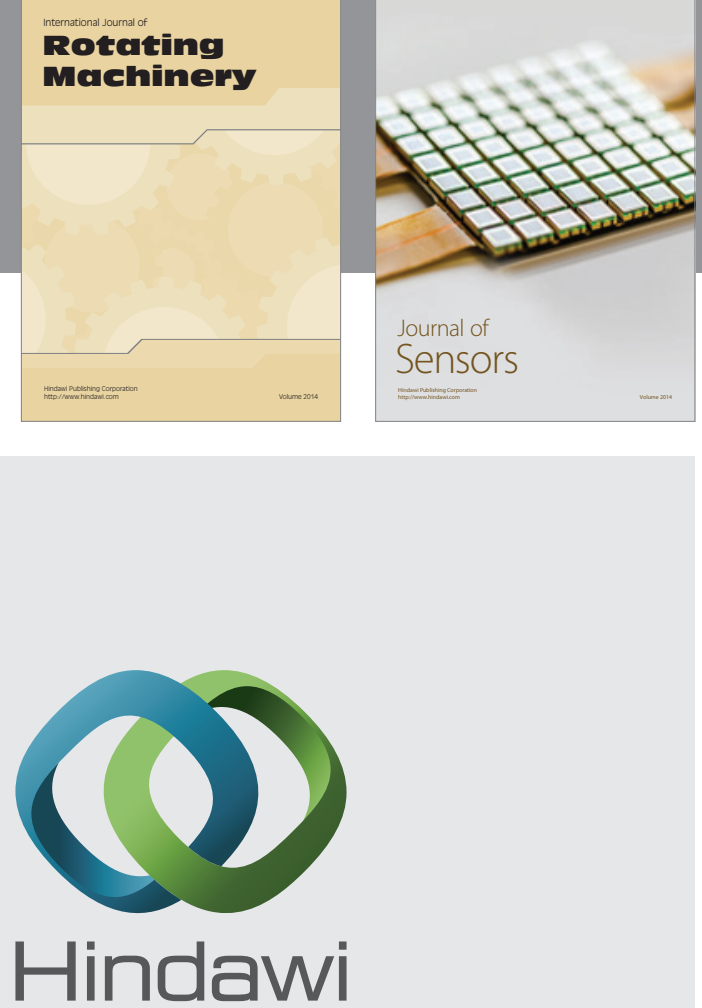

Submit your manuscripts at http://www.hindawi.com
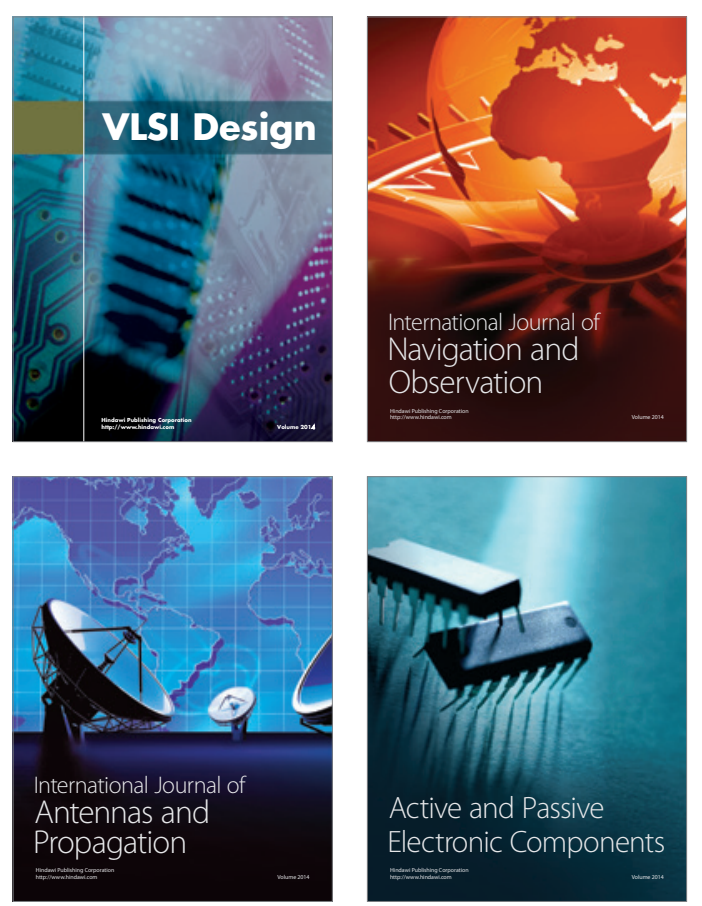
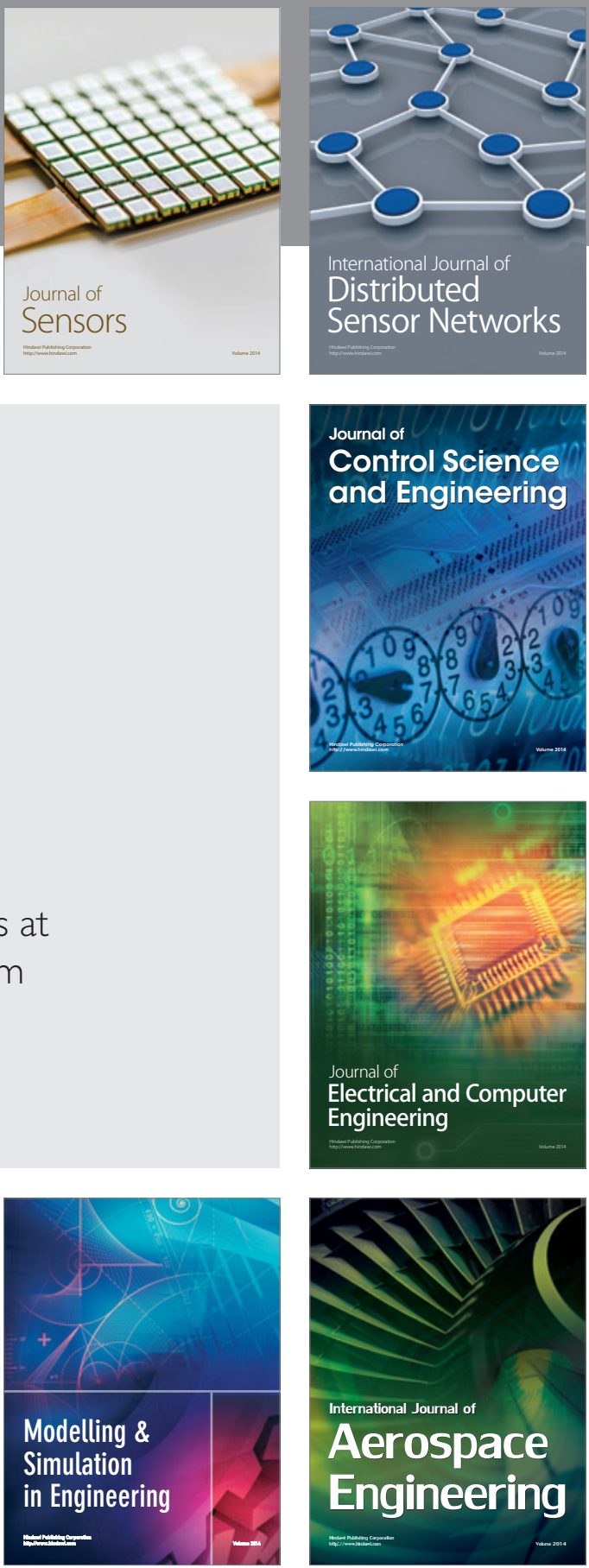

Journal of

Control Science

and Engineering
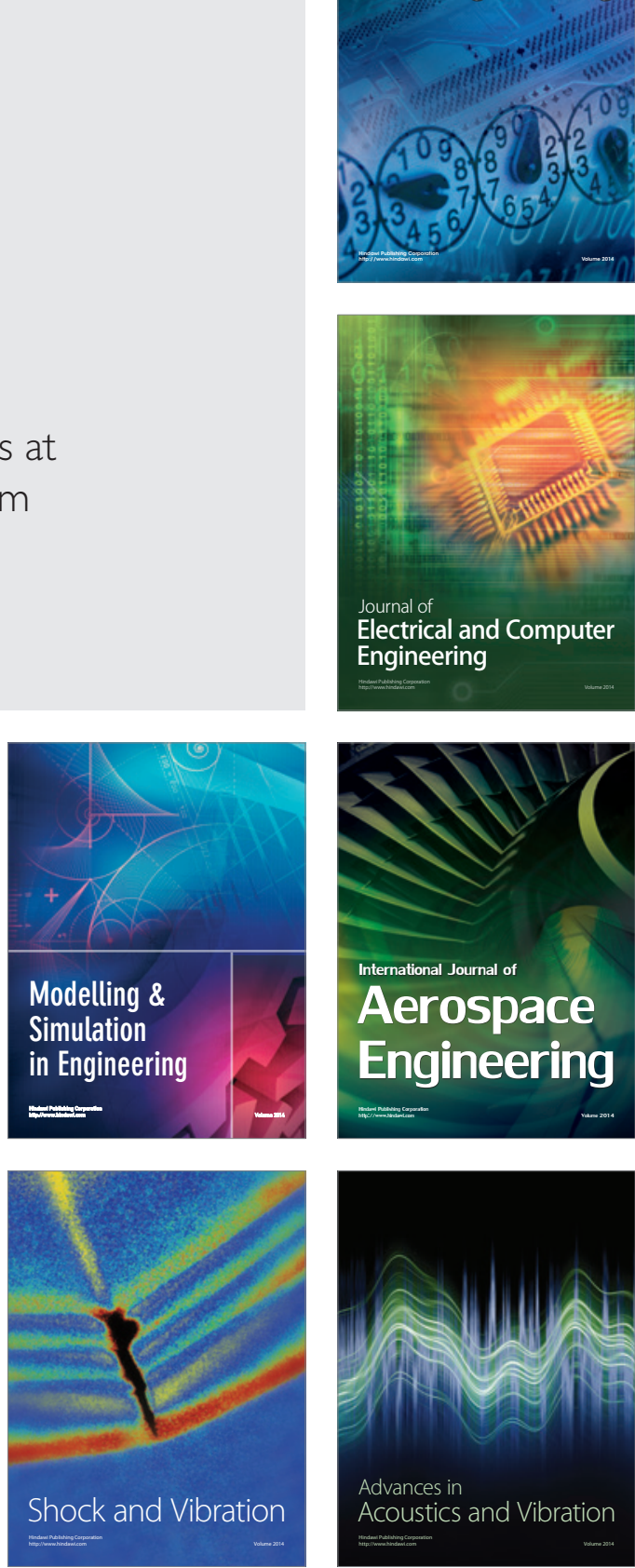